\title{
Validation of the ligase detection reaction fluorescent microsphere assay for the detection of Plasmodium falciparum resistance mediating polymorphisms in Uganda
}

\author{
Sheila Nankoberanyi ${ }^{1,3}$, George W Mbogo ${ }^{1,3}$, Norbert P LeClair ${ }^{2}$, Melissa D Conrad ${ }^{2}$, Patrick Tumwebaze ${ }^{1,3}$,
} Stephen Tukwasibwe ${ }^{1,3}$, Moses R Kamya ${ }^{1,3}$, Jordan Tappero ${ }^{4}$, Samuel L Nsobya ${ }^{1,3}$ and Philip J Rosenthal ${ }^{*^{*}}$

\begin{abstract}
Background: Malaria remains a major public health problem, and its control has been hampered by drug resistance. For a number of drugs, Plasmodium falciparum single nucleotide polymorphisms (SNPs) are associated with altered drug sensitivity and can be used as markers of drug resistance. Several techniques have been studied to assess resistance markers. The most widely used methodology is restriction fragment length polymorphism (RFLP) analysis. The ligase detection reaction fluorescent microsphere (LDR-FM) assay was recently shown to provide high throughput assessment of $P$. falciparum SNPs associated with drug resistance. The aim of this study was to validate the reliability and accuracy of the LDR-FM assay in a field setting.

Methods: For 223 samples from a clinical trial in Tororo, Uganda in which P. falciparum was identified by blood smear, DNA was extracted from dried blood spots, genes of interest were amplified by PCR, amplicons were analysed by both RFLP and LDR-FM assays, and results were compared.

Results: SNP prevalence (wild type/mixed/mutant) with RFLP analysis was 8/5/87\% for pfcrt K76T, 34/37/29\% for pfmdr1 N86Y, 64/17/19\% for pfmdr1 Y184F, and 42/21/37\% for pfmdr1 D1246Y. These prevalences with the LDR-FM assay were $7 / 5 / 88 \%, 31 / 24 / 45 \%, 62 / 20 / 18 \%$, and $48 / 19 / 33 \%$ for the four SNPs, respectively. Combining mixed and mutant outcomes for analysis, agreement between the assays was $97 \%(K=0.77)$ for pfcrt $K 76 T, 79 \%(K=0.55)$ for pfmdr1 N86Y, 83\% (K=0.65) for pfmdr1 Y184F, and 91\% ( $K=0.82)$ for pfmdr1 D1246Y, with most disagreements due to discrepant readings of mixed genotypes.

Conclusion: The LDR-FM assay provides a high throughput, relatively inexpensive and accurate assay for the surveillance of $P$. falciparum SNPs associated with drug resistance in resource-limited countries.
\end{abstract}

Keywords: Plasmodium falciparum, Malaria, Fluorescent microsphere assay, Drug resistance, Polymorphisms

\section{Background}

Malaria, especially that caused by Plasmodium falciparum, remains one of the most important infectious diseases in the world. The treatment and control of malaria has been greatly hampered by parasite resistance to available drugs. With widespread resistance to older drugs, artemisinin-based combination therapy (ACT) is now

\footnotetext{
* Correspondence: prosenthal@medsfgh.ucsf.edu

${ }^{2}$ Department of Medicine, University of California, Box 0811, San Francisco, CA 94143, USA

Full list of author information is available at the end of the article
}

the standard of care for the treatment of falciparum malaria. In Uganda, artemether-lumefantrine (AL) was introduced as first-line treatment for uncomplicated malaria in 2006 [1].

Mechanisms of resistance to anti-malarial drugs are incompletely understood. For chloroquine and amodiaquine, the K76T mutation in the pfcrt gene, which encodes a putative drug transporter, is the principal mediator of resistance [2]. Polymorphisms in another gene, pfmdr1, which encodes a protein homologous to transporters that mediate drug resistance in other organisms, modulate levels of 
sensitivity to multiple drugs [3]. In Africa, the pfmdr1 N86Y, Y184F and D1246Y polymorphisms are common, and the $86 \mathrm{Y}$ and $1246 \mathrm{Y}$ mutations are associated with decreased sensitivity to chloroquine and amodiaquine [4-6]. Interestingly, wild type sequences at these same alleles lead to decreased sensitivity to artemisinins and the ACT partner drugs lumefantrine and mefloquine $[5,7,8]$. Given the limited arsenal of effective ACT and early signs of artemisinin resistance in Southeast Asia $[9,10]$, there is a need for efficient surveillance of Ugandan parasites for genetic polymorphisms that may mediate resistance to the most important anti-malarial drugs.

Several techniques have been developed to detect single nucleotide polymorphisms (SNPs) associated with $P$. falciparum drug resistance. The most widely used is restriction fragment length polymorphism (RFLP) analysis [11], which is reliable, but fairly expensive and labour intensive. Other relatively low throughput methodologies include direct DNA sequencing, mutation-specific PCR [12], dot-blot probe hybridization [13], molecular beacons [14], and single-nucleotide primer extension [15]. Other techniques that have provided improved throughput include polymorphism-specific microarrays [16], melting curve analysis [17,18] and quantitative PCR [19-21]. Each of these methodologies has challenges, especially in resource-limited settings, including cost and availability of required instruments.

The ligase detection reaction fluorescent microsphere (LDR-FM) assay allows multiplex assessment of multiple $P$. falciparum SNPs [22]. It was recently shown that this assay is accurate and also less expensive and less labour intensive compared to RFLP analysis [23]. This new study compared the LDR-FM assay with RFLP analysis for the detection of key resistance-mediating $P$. falciparum SNPs in samples from a Ugandan clinical trial, with assays performed in parallel at a Ugandan laboratory.

\section{Methods}

\section{Samples for analysis}

Control parasite DNA was obtained from the Malaria Research and Reference Reagent Resource Center. Field samples were from a longitudinal anti-malarial drug efficacy trial in Tororo, Uganda, the details of which have been published [24]. Briefly, 351 children aged four to 12 months were enrolled and randomized to receive either AL or dihydroartemisinin-piperaquine (DP) for each episode of uncomplicated malaria between 2007 and 2012.

All first episodes of falciparum malaria and all recurrent malaria episodes presenting 84 or more days after prior treatment were studied. Parasite densities were estimated by counting the number of asexual parasites per 200 white blood cells and calculating parasites per $\mu \mathrm{L}$, assuming a white blood cell count of 8,000 cells $/ \mu \mathrm{L}$. The study was approved by the Uganda National Council of Science and Technology and the Institutional Review Boards of Makerere University College of Health Sciences and the University of California, San Francisco, USA.

\section{RFLP analysis}

DNA was extracted from filter paper with Chelex resin [25] and alleles were identified by nested PCR (see Additional file 1 for primers) followed by RFLP analysis, as previously described [26,27]. Briefly, regions of interest were amplified, PCR products were treated with polymorphism-specific restriction endonucleases (ApoI for $p f c r t$ K76T, AflIII for $p f m d r 1$ N86Y, DraI for pfmdr1 Y184F, and BglII for pfmdr1 D1246Y), and the sizes of products were characterized by agarose gel electrophoresis to distinguish wild type, mutant and mixed alleles based on comparison with control reference strain DNA.

\section{LDR-FM analysis}

The extracted DNA was amplified by PCR (see Additional file 2 for primers), as previously described [23]. The amplicons were subjected to multiplex ligase detection reactions (see Additional file 3 for primers) in which bead-specific oligonucleotides and biotin were added, ligation products were hybridized to magnetic beads, and polymorphism prevalences were assessed fluorometrically in a multiplex format using a Magpix instrument (Luminex). Genotypes were determined based on comparisons with controls, with a minimum threshold of 400 MFI for each reaction and correction factors for each SNP, as previously described [23].

Table 1 LDR-FM readings for four SNPs in Plasmodium falciparum reference strains

\begin{tabular}{|c|c|c|c|c|c|c|c|c|c|}
\hline \multirow[t]{2}{*}{ Strain } & \multicolumn{6}{|c|}{ pfmdr 1} & \multicolumn{3}{|l|}{ pfort } \\
\hline & $86 N$ & $86 \mathrm{Y}$ & $184 Y$ & $184 \mathrm{~F}$ & $1246 \mathrm{D}$ & $1246 Y$ & CVMNK & CVIET & SVMNT \\
\hline 3D7 & 4,325 & 119 & 3,316 & 251 & 3,720 & 191 & 1,330 & 237 & 281 \\
\hline 7G8 & 3,680 & 187 & 197 & 4,087 & 123 & 1,452 & 458 & 741 & 3,133 \\
\hline DD2 & 214 & 1,689 & 3,810 & 256 & 4,773 & 153 & 210 & 2,660 & 214 \\
\hline $\mathrm{V} 1 / \mathrm{S}$ & 126 & 4,018 & 3,679 & 284 & 3,599 & 193 & 309 & 2,647 & 315 \\
\hline
\end{tabular}

Values shown are uncorrected mean fluorescence readings for three to five assays, each run in triplicate. For pfcrt, the haplotype represents amino acids $72-76$. Readings representing the known sequences at each allele are in bold type. 
Table 2 Baseline characteristics of the samples utilized in this study

\begin{tabular}{|c|c|c|}
\hline \multirow[t]{2}{*}{ Characteristic } & \multicolumn{2}{|l|}{ Treatment arm } \\
\hline & $\mathrm{AL}(\mathrm{n}=101)$ & $\mathrm{DP}(n=129)$ \\
\hline Mean age, months \pm SD & $30.4 \pm 14$ & $30.4 \pm 14$ \\
\hline $\begin{array}{l}\text { Mean parasite density, } \\
\text { geometric mean } \\
\text { cells/ } / \text { I (IQR) }\end{array}$ & $18,534(8160-74,277)$ & $14,164(4720-60,800)$ \\
\hline $\begin{array}{l}\text { Mean time since last } \\
\text { episode of malaria, } \\
\text { days }\end{array}$ & 174 & 166 \\
\hline Year of collection & 2008-2012 & 2008-2012 \\
\hline $\begin{array}{l}\text { Mean time between } \\
\text { collection and } \\
\text { assay (range) }\end{array}$ & 3.7 years $(1-5)$ & 3.6 years $(1-5)$ \\
\hline
\end{tabular}

$A L$ artemether-lumefantrine; $D P$ dihydroartemisinin-piperaquine; IQR interquartile range; $S D$ standard deviation.

\section{Statistical analysis}

Correlation of results between assays was assessed using kappa statistics.

\section{Results}

Analysis of plasmodium falciparum reference strains

The goal of this study was to validate the LDR-FM assay, using samples from a recent clinical trial, with assays performed at a molecular laboratory in Kampala, Uganda. The LDR-FM assay was first evaluated with DNA from laboratory adapted $P$. falciparum strains 3D7, 7G8, DD2 and V1/S. Three SNPs in pfmdr1 that are common in Uganda and a five-amino acid haplotype in $p f c r t$ that distinguishes chloroquine-sensitive and -resistant parasites with different geographic backgrounds were assessed [28]. Sequence determinations at all studied polymorphisms were straightforward, with background readings for unidentified SNPs five to ten-fold lower than the readings for correct identifications (Table 1).

\section{Analysis of clinical samples}

A total of 230 smear-positive clinical samples were analysed by both RFLP and LDR-FM assays. The characteristics describing these samples are shown in Table 2. Representative uncorrected fluorescence data for ten samples showed generally good discrimination of wild type, mixed and mutant genotypes (Table 3). Results were available from 223 samples for both assays and these were used for comparisons. Assays were unsuccessful for six RFLP and zero LDR-FM assays for $p f c r t$, seven RFLP and seven LDR-FM assays at pfmdr1 86, seven RFLP and seven LDR-FM assays at pfmdr1 184, and three RFLP and one LDR-FM assays at pfmdr1 1246. SNP prevalences measured by RFLP analysis and with the LDR-FM assay were similar at all studied alleles (Table 4). Agreement between the assays was good, although results varied between the studied alleles (Figure 1). Most discrepancies were due to a mixed reading with one assay, compared to a pure mutant or wild type reading with the other assay. Combining mixed and mutant outcomes for analysis, agreement between the assays was 97\% $(\mathrm{K}=0.77)$ for $p f c r t \mathrm{~K} 76 \mathrm{~T}, 79 \%(\mathrm{~K}=0.55)$ for $p f m d r 1 \mathrm{~N} 86 \mathrm{Y}$, $83 \%(\mathrm{~K}=0.65)$ for $p f m d r 1 \mathrm{Y} 184 \mathrm{~F}$, and $91 \%(\mathrm{~K}=0.82)$ for pfmdr1 D1246Y.

\section{Discussion}

The aim of this study was to validate the LDR-FM assay for the detection of SNPs associated with anti-malarial drug resistance in a Ugandan laboratory. A total of 230 smear-positive clinical samples were analysed for four SNPs associated with anti-malarial drug resistance using RFLP and LDR-FM assays, and results were compared.

Table 3 Representative LDR-FM results for ten clinical samples

\begin{tabular}{|c|c|c|c|c|c|c|c|c|c|c|}
\hline \multirow[t]{2}{*}{ Sample } & \multirow{2}{*}{$\begin{array}{l}\text { Parasite } \\
\text { density } \\
\text { (per } \mu \mathrm{l})\end{array}$} & \multicolumn{6}{|c|}{ pfmdr1 } & \multicolumn{3}{|c|}{ pfcrt } \\
\hline & & $86 \mathrm{~N}$ & $86 Y$ & $184 Y$ & $184 \mathrm{~F}$ & 1246D & $1246 Y$ & CVMNK & CVIET & SVMNT \\
\hline 1 & 12,560 & 3,386 & 106 & 3,600 & 209 & 2,018 & 101 & 1,235 & 231 & 174 \\
\hline 2 & 74,080 & 1,849 & 1,885 & 2,083 & 2,284 & 3,286 & 309 & 811 & 1,678 & 195 \\
\hline 3 & 35,120 & 812 & 2,937 & 177 & 4,031 & 4,140 & 365 & 232 & 2,115 & 195 \\
\hline 4 & 8,960 & 3,761 & 188 & 2,879 & 3,361 & 4,536 & 164 & 207 & 2,311 & 214 \\
\hline 5 & 24,560 & 4,081 & 125 & 4,068 & 322 & 3,386 & 93 & 162 & 2,438 & 163 \\
\hline 6 & 1,440 & 143 & 3,777 & 4,024 & 292 & 115 & 2,065 & 222 & 2,430 & 164 \\
\hline 7 & 25,520 & 1,502 & 3,754 & 3,928 & 1,788 & 2,496 & 1,881 & 304 & 2,440 & 163 \\
\hline 8 & 36,064 & 2,829 & 2,846 & 311 & 5,227 & 3,148 & 937 & 1,119 & 1,610 & 211 \\
\hline 9 & 18,320 & 2,677 & 132 & 3,154 & 555 & 4,254 & 143 & 1,097 & 1,262 & 243 \\
\hline 10 & 14,840 & 4,121 & 100 & 3,686 & 267 & 196 & 1,715 & 1,385 & 317 & 231 \\
\hline
\end{tabular}

Values shown are uncorrected mean fluorescence readings. Readings representing the sequence call at each allele after correction by subtraction of background are in bold type. 
Table 4 Genotype results as analysed by RFLP and LDR-FM assays

\begin{tabular}{|c|c|c|c|c|c|c|c|c|}
\hline \multirow[t]{2}{*}{ Genotype } & \multicolumn{2}{|c|}{ pfcrt K76T } & \multicolumn{2}{|c|}{ pfmdr1 N86Y } & \multicolumn{2}{|c|}{ pfmdr1 Y184F } & \multicolumn{2}{|c|}{ pfmdr1 D1246Y } \\
\hline & RFLP & LDR-FM & RFLP & LDR-FM & RFLP & LDR-FM & RFLP & LDR-FM \\
\hline Wild type & $17(8 \%)$ & $16(7 \%)$ & 76 (34\%) & 69 (31\%) & $143(64 \%)$ & 139 (62\%) & $94(42 \%)$ & $107(48 \%)$ \\
\hline Mixed & $12(5 \%)$ & $11(5 \%)$ & $83(37 \%)$ & 53 (24\%) & 38 (17\%) & 45 (20\%) & 47 (21\%) & $42(19 \%)$ \\
\hline Mutant & 194 (87\%) & 196 (88\%) & $64(29 \%)$ & $101(45 \%)$ & $42(19 \%)$ & $39(18 \%)$ & $82(37 \%)$ & $74(33 \%)$ \\
\hline
\end{tabular}

The numbers of samples with each genotype and percentages of total assignments are shown.

It is important to note that both systems have potential for errors in misclassification, in particular due to challenges in distinguishing pure and mixed genotypes at each allele of interest. As seen in a prior study, SNP prevalences measured by RFLP and LDR-FM analyses were similar at the studied alleles, with most discrepancies between assays due to different calls for mixed genotypes, and with DNA sequencing showing that for 8 of 9 discrepant readings the LDR-FM result was correct [23].

Several techniques have been assessed to detect SNPs associated with $P$. falciparum anti-malarial drug resistance, each with potential advantages and disadvantages in a resource-limited setting. Of particular importance is availability of equipment necessary for high throughput methods. The LDR-FM assay requires an expensive device, but this unit can provide a range of assays, including measurements of serum cytokine levels and antibody reactivity, suggesting that it will be of value for many field-based laboratories. Reagent costs for the LDR-FM assay are also significant, but this is the case with all molecular assays, and recent estimates suggested that the assay provides results at about half the reagent costs of RFLP assessments [23]. Further, throughput was estimated to be five to ten-fold better with the LDR-FM assay compared to RFLP analysis, offering large potential savings in personnel costs.

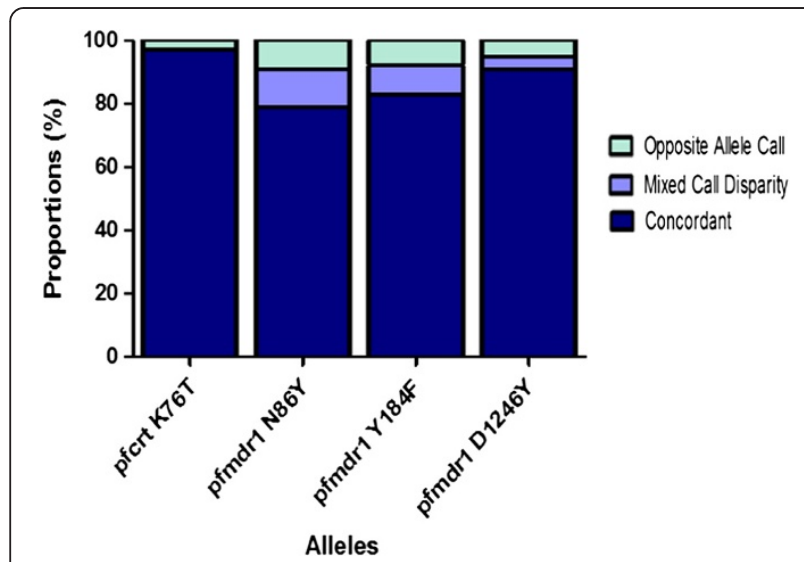

Figure 1 Agreement between RFLP and LDR-FM assays. Results are shown for samples with readings from both assays at the indicated alleles.

\section{Conclusions}

The LDR-FM assay, when performed in a developingworld laboratory, provided accurate assessment of SNPs associated with anti-malarial drug resistance. This method offers relatively high throughput and low cost, hence it will be used for large-scale surveillance of $P$. falciparum polymorphisms of interest in ongoing studies in Uganda [29]. For other field-based laboratories with access to Magpix instrumentation, this system may offer the most practical means of large-scale surveillance of $P$. falciparum genetic polymorphisms.

\section{Additional files}

Additional file 1: PCR primers for RFLP analyses.

Additional file 2: PCR primers for LDR-FM analyses.

Additional file 3: LDR primers for LDR-FM analyses.

\section{Abbreviations}

RFLP: Restriction fragment length polymorphism; LDR-FM: Ligase detection reaction fluorescent microsphere; SNP: Single nucleotide polymorphism; AL: Artemether-lumefantrine; DP: Dihydroartemisinin-piperaquine;

$\mathrm{ACT}$ : Artemisinin-based combination therapy.

\section{Competing interests}

All authors declare that there are no competing interests.

\section{Authors' contributions}

SN ran the LDR-FM assays, analysed the data and wrote the first draft of the manuscript. GWM ran the RFLP assays and helped with data analysis. NPL, MDC, PT, ST, and SLN provided advice and technical support for optimization of the LDR-FMA protocol in Uganda. MRK and JT oversaw design and completion of the clinical trial that provided samples for this study. PJR assisted in the design the study, obtained funding, and wrote the first draft of the manuscript. All authors contributed to preparation of this manuscript and read and approved the final draft.

\section{Acknowledgments}

We thank the children studied in the clinical trial that provided samples for our analyses, their parents or guardians, the study personnel and the molecular biology team in Kampala for their assistance during the study. This study was funded by an International Center of Excellence in Malaria Research grant (Al089674) and a Fogarty International Center training grant (TW007375), both from the National Institutes of Health. The clinical trial that provided samples for this study was funded by the Centers for Disease Control and Prevention and the Doris Duke Charitable Foundation.

\section{Author details}

${ }^{1}$ Infectious Diseases Research Collaboration, Kampala, Uganda. ${ }^{2}$ Department of Medicine, University of California, Box 0811, San Francisco, CA 94143, USA. ${ }^{3}$ Makerere University, Kampala, Uganda. ${ }^{4}$ Centers for Disease Control and Prevention, Center for Global Health, Atlanta, GA, USA. 
Received: 18 November 2013 Accepted: 21 February 2014

Published: 14 March 2014

\section{References}

1. Yeka A, Gasasira A, Mpimbaza A, Achan J, Nankabirwa J, Nsobya S, Staedke SG, Donnelly MJ, Wabwire-Mangen F, Talisuna A, Dorsey G, Kamya MR Rosenthal PJ: Malaria in Uganda: Challenges to control on the long road to elimination. I. Epidemiology and current control efforts. Acta Trop 2012, 121:184-195.

2. Fidock DA, Nomura T, Talley AK, Cooper RA, Dzekunov SM, Ferdig MT, Ursos LM, Sidhu AB, Naude B, Deitsch KW, Su XZ, Wootton JC, Roepe PD, Wellems TE: Mutations in the $P$. falciparum digestive vacuole transmembrane protein PfCRT and evidence for their role in chloroquine resistance. Mol Cell 2000 6:861-871

3. Valderramos SG, Fidock DA: Transporters involved in resistance to antimalarial drugs. Trends Pharmacol Sci 2006, 27:594-601.

4. Dokomajilar C, Lankoande ZM, Dorsey G, Zongo I, Ouedraogo JB, Rosenthal PJ: Roles of specific plasmodium falciparum mutations in resistance to amodiaquine and sulfadoxine-pyrimethamine in Burkina Faso. Am J Trop Med Hyg 2006, 75:162-165.

5. Humphreys GS, Merinopoulos I, Ahmed J, Whitty CJ, Mutabingwa TK, Sutherland CJ, Hallett RL: Amodiaquine and artemether-lumefantrine select distinct alleles of the plasmodium falciparum mdr1 gene in tanzanian children treated for uncomplicated malaria. Antimicrob Agents Chemother 2007, 51:991-997.

6. Nawaz F, Nsobya SL, Kiggundu M, Joloba M, Rosenthal PJ: Selection of parasites with diminished drug susceptibility by amodiaquine-containing antimalarial regimens in Uganda. J Infect Dis 2009, 200:1650-1657.

7. Dokomajilar C, Nsobya SL, Greenhouse B, Rosenthal PJ, Dorsey G: Selection of plasmodium falciparum pfmdr1 alleles following therapy with artemether-lumefantrine in an area of Uganda where malaria is highly endemic. Antimicrob Agents Chemother 2006, 50:1893-1895.

8. Mwai L, Kiara SM, Abdirahman A, Pole L, Rippert A, Diriye A, Bull P, Marsh K, Borrmann S, Nzila A: In vitro activities of piperaquine, lumefantrine, and dihydroartemisinin in Kenyan plasmodium falciparum isolates and polymorphisms in pfcrt and pfmdr1. Antimicrob Agents Chemother 2009, 53:5069-5073.

9. Noedl H, Se Y, Schaecher K, Smith BL, Socheat D, Fukuda MM: Evidence of artemisinin-resistant malaria in western Cambodia. N Engl J Med 2008, 359:2619-2620.

10. Dondorp AM, Nosten F, Yi P, Das D, Phyo AP, Tarning J, Lwin KM, Ariey F. Hanpithakpong W, Lee SJ, Ringwald P, Silamut K, Imwong M, Chotivanich K, Lim P, Herdman T, An SS, Yeung S, Singhasivanon P, Day NP, Lindegardh N, Socheat $\mathrm{D}$, White $\mathrm{NJ}$ : Artemisinin resistance in plasmodium falciparum malaria. N Engl J Med 2009, 361:455-467.

11. Duraisingh MT, Curtis J, Warhurst DC: Plasmodium falciparum: detection of polymorphisms in the dihydrofolate reductase and dihydropteroate synthetase genes by PCR and restriction digestion. Exp Parasitol 1998, 89:1-8.

12. Dorsey G, Kamya MR, Singh A, Rosenthal PJ: Polymorphisms in the plasmodium falciparum pfcrt and pfmdr-1 genes and clinical response to chloroquine in Kampala, Uganda. J Infect Dis 2001, 183:1417-1420.

13. Ranford-Cartwright LC, Johnston KL, Abdel-Muhsin AM, Khan BK, Babiker HA: Critical comparison of molecular genotyping methods for detection of drug-resistant plasmodium falciparum. Trans R Soc Trop Med Hyg 2002, 96:568-572

14. Durand R, Eslahpazire J, Jafari S, Delabre JF, Marmorat-Khuong A, di Piazza JP, Le Bras J: Use of molecular beacons to detect an antifolate resistance-associated mutation in plasmodium falciparum. Antimicrob Agents Chemother 2000, 44:3461-3464.

15. Nair S, Brockman A, Paiphun L, Nosten F, Anderson TJ: Rapid genotyping of loci involved in antifolate drug resistance in plasmodium falciparum by primer extension. Int J Parasitol 2002, 32:852-858.

16. Crameri A, Marfurt J, Mugittu K, Maire N, Regos A, Coppee JY, Sismeiro O, Burki R, Huber E, Laubscher D, Puijalon O, Genton B, Felger I, Beck HP: Rapid microarray-based method for monitoring of all currently known single-nucleotide polymorphisms associated with parasite resistance to antimalaria drugs. J Clin Microbiol 2007, 45:3685-3691.

17. Decuypere S, Elinck E, Van Overmeir C, Talisuna AO, D'Alessandro U, Dujardin JC: Pathogen genotyping in polyclonal infections: application of a fluorogenic polymerase-chain-reaction assay in malaria. $J$ Infect Dis 2003, 188:1245-1249.

18. Daniels R, Ndiaye D, Wall M, McKinney J, Sene PD, Sabeti PC, Volkman SK, Mboup S, Wirth DF: Rapid, field-deployable method for genotyping and discovery of single-nucleotide polymorphisms associated with drug resistance in plasmodium falciparum. Antimicrob Agents Chemother 2012, 56:2976-2986

19. de Monbrison F, Raynaud D, Latour-Fondanaiche C, Staal A, Favre S, Kaiser K, Peyron F, Picot S: Real-time PCR for chloroquine sensitivity assay and for pfmdr1-pfcrt single nucleotide polymorphisms in plasmodium falciparum. J Microbiol Methods 2003, 54:391-401.

20. Purfield A, Nelson A, Laoboonchai A, Congpuong K, McDaniel P, Miller RS, Welch K, Wongsrichanalai C, Meshnick SR: A new method for detection of pfmdr1 mutations in plasmodium falciparum DNA using real-time PCR. Malar J 2004, 3:9.

21. Kamau E, Alemayehu S, Feghali KC, Tolbert LS, Ogutu B, Ockenhouse CF: Development of a TaqMan allelic discrimination assay for detection of single nucleotides polymorphisms associated with anti-malarial drug resistance. Malar J 2012, 11:23.

22. Carnevale EP, Kouri D, DaRe JT, McNamara DT, Mueller I, Zimmerman PA: A multiplex ligase detection reaction-fluorescent microsphere assay for simultaneous detection of single nucleotide polymorphisms associated with plasmodium falciparum drug resistance. J Clin Microbiol 2007, 45:752-761.

23. LeClair NP, Conrad MD, Baliraine FN, Nsanzabana C, Nsobya SL, Rosenthal PJ: Optimization of a ligase detection reaction-fluorescent microsphere assay for characterization of resistance-mediating polymorphisms in African samples of plasmodium falciparum. J Clin Microbio/ 2013, 51:2564-2570.

24. Arinaitwe E, Sandison TG, Wanzira H, Kakuru A, Homsy J, Kalamya J, Kamya MR, Vora N, Greenhouse B, Rosenthal PJ, Tappero J, Dorsey G: Artemether-lumefantrine versus dihydroartemisinin-piperaquine for falciparum malaria: a longitudinal, randomized trial in young Ugandan children. Clin Infect Dis 2009, 49:1629-1637.

25. Plowe CV, Djimde A, Bouare M, Doumbo O, Wellems TE: Pyrimethamine and proguanil resistance-conferring mutations in plasmodium falciparum dihydrofolate reductase: polymerase chain reaction methods for surveillance in Africa. Am J Trop Med Hyg 1995, 52:565-568.

26. Djimde A, Doumbo OK, Cortese JF, Kayentao K, Doumbo S, Diourte Y, Dicko A, Su XZ, Nomura T, Fidock DA, Wellems TE, Plowe CV: A molecular marker for chloroquine-resistant falciparum malaria. N Engl J Med 2001, 344:257-263.

27. Duraisingh MT, Jones $P$, Sambou I, von Seidlein $L$, Pinder M, Warhurst DC: The tyrosine- 86 allele of the pfmdr 1 gene of plasmodium falciparum is associated with increased sensitivity to the anti-malarials mefloquine and artemisinin. Mol Biochem Parasitol 2000, 108:13-23.

28. Mehlotra RK, Mattera G, Bockarie MJ, Maguire JD, Baird JK, Sharma YD, Alifrangis M, Dorsey G, Rosenthal PJ, Fryauff DJ, Kazura JW, Stoneking M, Zimmerman PA: Discordant patterns of genetic variation at two chloroquine resistance loci in worldwide populations of the malaria parasite plasmodium falciparum. Antimicrob Agents Chemother 2008, 52:2212-2222

29. Talisuna A, Adibaku S, Dorsey G, Kamya MR, Rosenthal PJ: Malaria in Uganda: challenges to control on the long road to elimination. II. The path forward. Acta Trop 2012, 121:196-201.

doi:10.1186/1475-2875-13-95

Cite this article as: Nankoberanyi et al:: Validation of the ligase detection reaction fluorescent microsphere assay for the detection of Plasmodium falciparum resistance mediating polymorphisms in Uganda. Malaria Journal 2014 13:95. 